\section{ASPIRATION OF THE SECRETIONS IN NEONATAL RESUSCITATION. AN EVIDENCE BASED APPROACH}

doi:10.1136/archdischild-2012-302724.1308

Al Toma, I Cuzino, A Cozinov, 0 Raluca. Neonatology, Life Memorial Hospital, Bucharest, Romania

Background and Aims Aspiration of the secretions at birth is a step performed in the care of the newborn immediately after delivery, but it is not supported by evidence-based data. Our study aim is to prove the suction of the secretions is a necessary step in neonatal resuscitation and care at delivery.

Method We studied 1154 consecutive cesarean section deliveries The care at birth was according to the AAP Resuscitation Guidelines, except the neonates were randomized to mandatory aspiration of the secretions at delivery by suction catheter ( $\mathrm{S}$ group) or clearing the secretions from the mouth when they are visible by gentle aspiration of the mouth ( $\mathrm{C}$ group). There were noted the time to first breath, need for bag and mask ventilation, occurrence of respiratory distress, need for mechanical ventilation, blood gas values at delivery.

Results $25 / 577$ of the neonates in the $S$ group developed respiratory grunting after delivery compared with $42 / 577$ neonates in the $\mathrm{C}$ group $(\mathrm{p}<0.001)$. The need of bag and mask ventilation at birth was similar between the groups (10/577 C; 11/577 S group). When stratified for gestational age(GA), 12/253 neonates in the $\mathrm{S}$ group with GA less than 38 weeks presented with respiratory distress and grunting after delivery compared with $35 / 260$ in the $C$ group $(\mathrm{p}<0.001)$.

Conclusions Aspiration of the secretions at birth is a necessary step in the care at birth of the newborns born by cesarean section, especially if they are 38 weeks or less gestational age.

\section{ELEVATED 17-HYDROXYPROGESTERONE [17-0HP] LEVELS: A FETOPLACENTAL MECHANISM TO PREVENT PRETERM BIRTH?}

doi:10.1136/archdischild-2012-302724.1309

'MP Sherman, 'S Younger, ${ }^{1,2 J}$ Sherman. 'Child Health; ${ }^{2}$ Sinclair School of Nursing, University of Missouri - Columbia, Columbia, MO, USA

Background and Aims Elevated 17-Hydroxyprogesterone [17$\mathrm{OHP}$ ] levels in preterm infants are often false positives. We theorized the elevation was related to preterm labor [PTL] and not related to maternal or fetal disease. We surmised that an elevated fetoplacental 17-OHP is akin to obstetrical therapy with progesterone to prevent preterm birth

Methods Infants with congenital adrenal hyperplasia were excluded. Nucleated red blood cell count [nRBC] was a marker of chronic fetal hypoxia or severe preeclampsia and C-reactive protein [CRP] was an indicator of perinatal infection. Using an effect size of 0.5 with a two-tail test, an alpha of 0.05 , and a power of 0.8 , at least 66 infants were needed for this study.

Results Fifty-three male and 47 female infants had a mean gestational age of 32.4 and 31.2 weeks, respectively. No mothers received therapy with progesterone for PTL; however, $84 \%$ of mothers had PTL. Pearson's correlation showed lower birth weight $(r=-0.65$, $\mathrm{p}<0.001)$, gestational age $(\mathrm{r}=-0.64, \mathrm{p}<0.001)$, and one minute APGAR scores $(r=-0.21, p=0.04)$ were significantly associated with increased 17-OHP levels. There was no correlation between CRP or $\mathrm{nRBC}$ and 17-OHP levels. After an initial elevated 17-OHP, repeat testing was normal.

Conclusions Intrapartum infection and preeclampsia did not correlate with elevated 17-OHP levels as previously reported. An elevated 17-OHP in preterm infants is associated with PTL and birth. Whether an elevated 17-OHP level at birth confers protection to preterm infants from morbidity or death requires additional investigation.

\section{A STUDY OF PROFESSIONALS' OPINIONS OF HOME DELIVERIES: A CROSS SECTIONAL STUDY}

doi:10.1136/archdischild-2012-302724.1310

1,2,3T Thornton, ${ }^{4}$ P Clarke, ${ }^{5} \mathrm{DA}$ McNutt, ${ }^{6} \mathrm{~A}$ Curley. ${ }^{1}$ Queen Elizabeth Hospital, Kings Lynn,

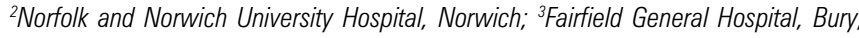
${ }^{4}$ Neonatology Intensive Care Unit, Norfolk and Norwich University Hospital, Norwich ${ }^{5}$ Fairfield General Hospital, Manchester; ${ }^{6}$ Addenbrookes Hospital, Cambridge, UK

Background and Aims A recent Government policy drive is to increase home delivery rates. Data are lacking about whether this strategy is embraced by perinatal healthcare professionals. Our aim was to examine opinions regarding home deliveries held by consultant paediatricians, neonatologists, gynaecologists, obstetricians, GPs and midwives.

Methods Cross-sectional survey of UK professionals in East Anglia. Likert scales ranging from 0-10 assessed professionals' general experiences of and enthusiasm for home birthing and support for the Government's plan.

Results $52 \%$ of professionals responded, including $68 \%$ of Paediatricians. Paediatricians and Neonatologists generally reported negative experiences of home delivery and were considerably less enthusiastic regarding home deliveries than any other professionals.

Paediatricans generally held a negative outlook on home delivery [median 4, IQ 3-5] and were in opposition to the government's plan [median 3, IQ 2-5], whilst midwives were more enthusiastic about home delivery than any other profession [median 9, IO 8-10, $\mathrm{p}<0.0001]$ and were more likely to support the government plan to increase the rate of home deliveries [median 8.5, IQ 7-10, $\mathrm{p}<0.0001$ ]. GP's, obstetricians and gynaecologists tended to give more neutral or negative opinions towards home birth [GP (median 5, IQ 3-7.5) ObGyn (median 5, IQ 2-7)] and towards the government's plan [GP (median 5, IQ 2-6) ObGyn (median 5, IQ 2-5)].

Conclusions Negative experiences and opinions of perinatal healthcare professionals regarding home delivery may adversely affect its uptake by women and will need to be addressed if the Government's plan to increase home delivery rates is to succeed.

\section{1 'TUBES' AND CATHETER POSITIONS IN NEONATES TRANSFERRED TO A TERTIARY NEONATAL INTENSIVE CARE UNIT OVER A 2 YEAR PERIOD}

doi:10.1136/archdischild-2012-302724.1311

'G Nepali, ${ }^{2} \mathrm{M}$ Tasbihi, ${ }^{1} \mathrm{~J}$ Egyepong. ' Neonatal Intensive Care Unit, Luton and Dunstable Hospital NHS Trust; ${ }^{2}$ Department of Paediatric, Luton \& Dunstable University Hospital NHS Trust, Luton, UK

\section{Introduction}

- Endotracheal tubes (ETT), Chest tubes (CT), Nasogastric tubes (NGT), umbilical artery and venous catheters (UAC, UVC), Long lines (LL) are crucial in the management of babies transferred and admitted to neonatal intensive care units (NICU). Optimal positions must be ascertained before transfer and on admission to avoid complications.

- To the best of our knowledge, there has not been any published data looking at admission positions of all these tubes and catheters.

Aim

To determine:

- positions of these tubes and lines on admission of babies transferred for intensive care to a tertiary NICU.

- any radiological and other complications that may have been associated with sub-optimally placement on admission.

Methods

Retrospective study

- 01/2010-12/2011 
- All babies transferred in

- Inclusion criteria: Admission X-ray done within 12 hrs

\section{Results}

- 148 babies were admitted for tertiary neonatal care of which 127 met inclusion criteria. Patients were stratified as $<1 \mathrm{~kg}$, $1-2 \mathrm{~kg}$ and $>2 \mathrm{~kg}$.

Correctly positioned tubes were as follows:

- < 1 kg: 33\% ETT, 81\%NGT, 48\% UAC

- 1-2 kg: 31\% ETT, 100\% NGT, 33\%UAC

- >2kg: 54\% ETT, $100 \%$ NGT, 31\%UAC

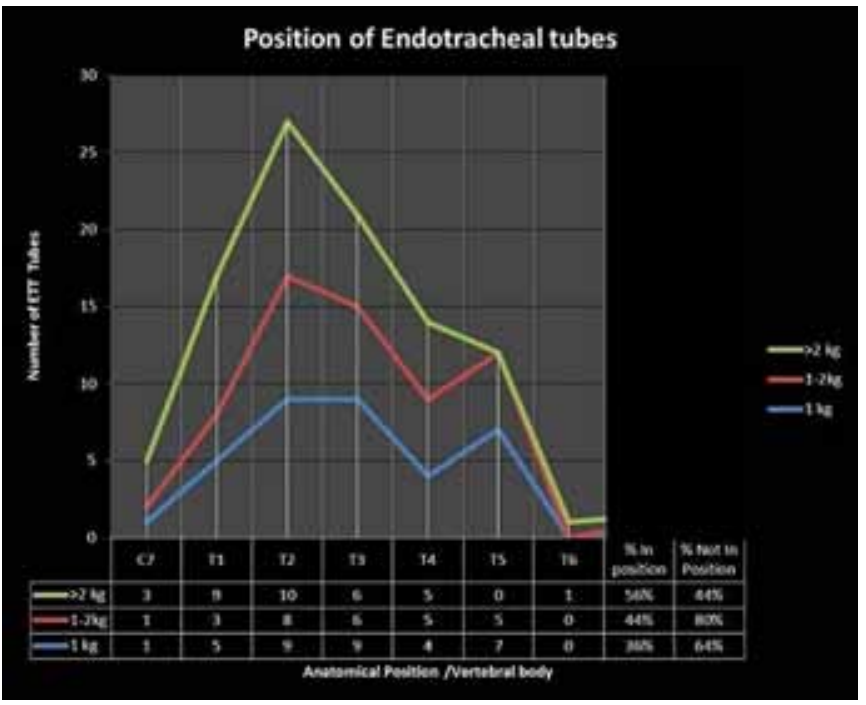

Abstract 1311 Figure 1 Graph of Position of Endotracheal Tube.

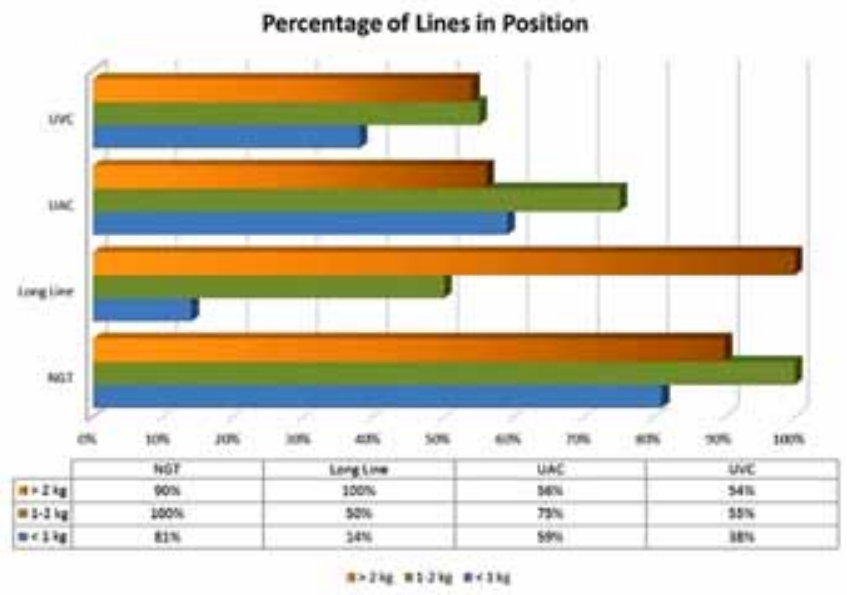

Abstract 1311 Figure 2 Graphs of Position OF UAC, UVC, LongLine, NGT

\section{Conclusion}

- Infants less than $1 \mathrm{~kg}$ were at higher risk of suboptimally positioned tubes and lines.

- Position prior to transfer and on admission must be ascertained to minimise complications.

\section{2 STABILISING PRETERM INFANTS $(<32$ WEEKS) IN THE DELIVERY SUITE: CURRENT CLINICAL PRACTICE IN THE UK}

doi:10.1136/archdischild-2012-302724.1312
1.2Y Singh, ${ }^{2} \mathrm{~S}$ Oddie. ${ }^{1}$ Neonatal Medicine, The Leeds Teaching Hospitals NHS Trust; Leeds; ${ }^{2}$ Neonatal Medicine, Bradford Teaching Hospitals, Bradford, UK

Background Resuscitation guideline for preterm infants has evolved over the last two decades but this still lacks standardisation and clear recommendations. Clinical practice in stabilising preterm infants in the delivery suite may vary from unit to unit.

Aims and objectives To find out the current clinical practice in the UK in stabilising the preterm infants in the delivery suite.

Study Design and methods Questionnaire based study carried out via internet tool (SurveyMonkey) followed by telephone interview from non-responders. Questionnaire completed by consultants, registrars or senior neonatal sisters (Band 6 and above).

Results $100 \%$ responses from all the 222 units providing neonatal care. $96 \%$ units (113 of 222 units) use plastic bags for thermoregulation in preterm infants although clinical practice varies from 27-32 weeks of gestation under what they use plastic bags.

$56 \%$ units (123 of 222 units) provide prophylactic CPAP in preterm infants to prevent or treat RDS. Face mask with adjustable positive end expiratory pressure (PEEP) valve was the commonest (50\%; 111 of 222 units) means of providing prophylactic CPAP. But for ventilated babies 70\% units (154 of 222 units) provide PEEP routinely.

$42 \%$ units (93 of 222 units) use start resuscitation of preterm infants in bended oxygen, $33 \%$ in air, and $17 \%$ use $100 \%$ oxygen. $64 \%$ units (143 of 222 units) use oxygen saturation monitor in the delivery suite while $28 \%$ don't use it routinely.

Conclusion Current clinical practice in stabilising preterm infants in the delivery suite varies significantly from unit to unit in the UK

\section{CAN PRE-PREGNANCY BODY MASS INDEX IN GESTATIONAL DIABETES PREDICT NEONATAL BIRTH WEIGHT?}

doi:10.1136/archdischild-2012-302724.1313

S Beken, Ö Turhan İyidir, E Önal, A Eroğlu Altınova, F Baloş Törüner, N Çakır, Y Atalay. Gazi University Hospital, Ankara, Turkey

Background and Aim Gestational Diabetes Mellitus (GDM) is the glucose intolerance detected during pregnancy. The most common neonatal complication of these mothers is macrosomic or large for gestational age (LGA) babies. We evaluated the pre-pregnancy body mass index (PP-BMI) and the effects of glycemic control on the frequency of neonatal complications and macrosomia in GDM pregnancies.

Methods 87 GDM pregnancies were retrospectively enrolled in the study and divided into two groups: Group I, PP-BMI $<25.0 \mathrm{~kg} / \mathrm{m} 2$ (normal, $\mathrm{n}=29$ ), and Group II, PP-BMI $\geq 25 \mathrm{~kg} / \mathrm{m} 2$ (overweight, $\mathrm{n}=58$ ). Carpenter-Couston criterias modified from Workshop-Conference on Gestational Diabetes were used for GDM diagnosis. Infants born from these mothers were also divided as appropriate for gestational age (AGA) and LGA.

Results There were no differences with respect to age, gestational age at admission, mean $\mathrm{HbA1c}$ levels, mode of delivery and perinatal mortality between groups. On the other hand, number of LGA infants were significantly higher in Group II $[n=1(3.4 \%)$ vs $n=13$ $(22.4 \%) ; p=0.02]$. There were no difference about neonatal complications between groups including; hypoglysemia, sepsis, polycythemia, respiratory distress and hospitalization during neonatal period.

Conclusion Good glysemic control in GDM patients was not seem to be enough in reducing the LGA babies. Overweight paients should be treated before pregnancy, and during pregnancy good glycemic control must be assured so that LGA babies and neonatal complications can be decreased. 